\title{
Mature Placental Teratoma: Case Report
}

\author{
Nagehan Ozdemir Barisik ${ }^{1}$, Cem Cahit Barisik², Sevinc Keser ${ }^{1}$, Aylin Ege Gul ${ }^{1}$ \\ ${ }^{1}$ Department of Pathology, Dr. Lutfi Kirdar Kartal Education and Research Hospital, Istanbul, Turkey; ${ }^{2}$ Department of Radiology, \\ Medipol University, Istanbul, Turkey. \\ Email: nagehanob@yahoo.com
}

Received March 21 $1^{\text {st }}, 2013$; revised May $20^{\text {th }}$, 2013; accepted June $24^{\text {th }}, 2013$

Copyright (C) 2013 Nagehan Ozdemir Barisik et al. This is an open access article distributed under the Creative Commons Attribution License, which permits unrestricted use, distribution, and reproduction in any medium, provided the original work is properly cited.

\begin{abstract}
Placental teratoma is a very rare tumor. The tumor we present that lay between amnion and chorion contained disorganized skin and its appendages, bone, cartilage, and fat. There was no evidence of recognizable umblical cord. Our diagnosis was "mature teratoma of the placenta”. The distinction between teratoma and fetus acardius amorphus, besides the possible origin of a tumor in this site, is discussed with a brief of literature.
\end{abstract}

Keywords: Placenta; Teratoma; Fetus Amorphus

\section{Introduction}

Teratomas are neoplasms produced from totipotential embryonic germ cells and thus can be composed of virtually any type of tissue. They contain elements derived from multiple germ cell layers. The sites of occurence are, in order of frequency, the ovary, testis, anterior mediastinum, retroperitoneum, presacral and coccygeal regions [1,2]. Placenta is an extremely rare site for this tumor. Only a few cases have been reported since they were first described by Morvilli in 1925 [1-5]. They always lie between the amnion and chorion, usually on fetal surface of placenta but sometimes within the membranes [3]. Placental teratomas closely resemble a fetus amorphous but lack a recognizable umblical cord, and the organization and central skeletal formation of this condition $[3,4]$. Generally, they do not lead to a serious complication during the prenatal period and for the fetus [1]. Here, we present a placental teratoma that did not have an obstetrical complication.

\section{Case Report}

A 26-year-old pregnant women underwent a normal delivery of female infant weighing $3000 \mathrm{~g}$ with Apgar score of $8 / 10$. After the placenta was delivered, a tumor mass was found between the extraplacental amnion and chorion. Since the patient had no antenatal visits, we do not know if the tumor could have been detected antenatally by ultrasound examination.

The formalin-fixed placenta measured $14 \times 13 \times 4 \mathrm{~cm}$. The centrally inserted umblical cord was $25 \mathrm{~cm}$ long and contained two arteries and one vein. The mass measured $7 \times 6.5 \times 4 \mathrm{~cm}$ and was covered by membranes. The cut surface of tumor was solid, yellow in colour and markedly heterogenous, with adipose tissue, cartilage and bone structures (Figure 1).

On histological examination, the tumor was covered by skin and appendages including sweat glands, sebaceous glands, and well-developed hair follicles (Figure 2). The deeper layers of the tumor were composed of mature fat tissue and edematous loose connective tissue. Small blood vessels and peripheral nerve fibers with ganglion cells were scattered throughout the adipose tissue and striated muscle fibers. The central area of the tumor consisted of a mixture of cartilage and bone (Figures 3 and 4). No poorly differentiated components were found in the tumor. The rest of the placenta showed syncytial knots and some foci of calcification, which are features of the full-term placenta.

\section{Discussion}

Placental teratomas are rare tumours with an unclear histogenesis [4,5]. Widely accepted theory is the one based on the hypothesis of Fox and Butler-Manuel suggesting a primordial germ cell origin [1-6].

After the third week of development, primordial germ cells that arise in the dorsal wall of the yolk sac begin migration to the genital ridge along the dorsal mesentery of the hindgut. During this stage, some primordial germ cells may go astray and migrate to a more distant midline structure, like the mediastinum, where a teratoma of de- 


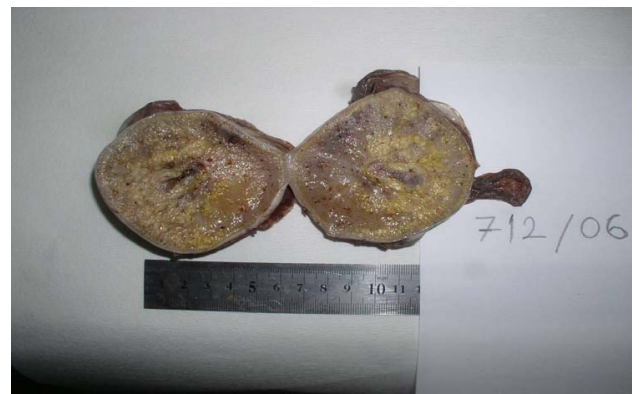

Figure 1. Macroscopic apperance of teratoma.

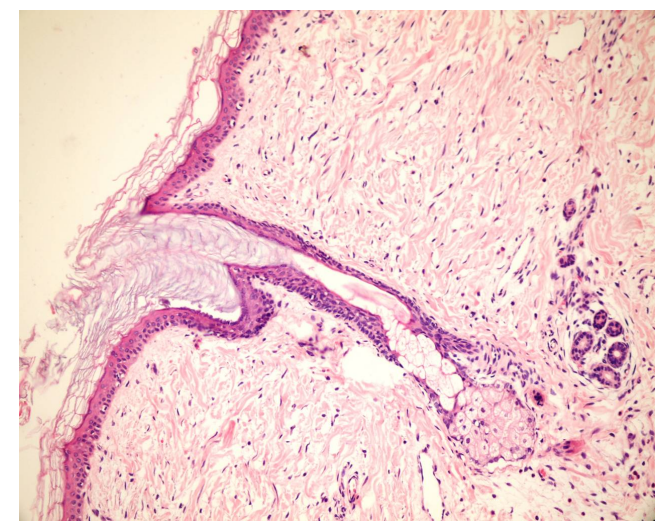

Figure 2. Superficial mature keratinizing squamous epitelium. Hematoxylin \& Eosin [H\&E × 100].

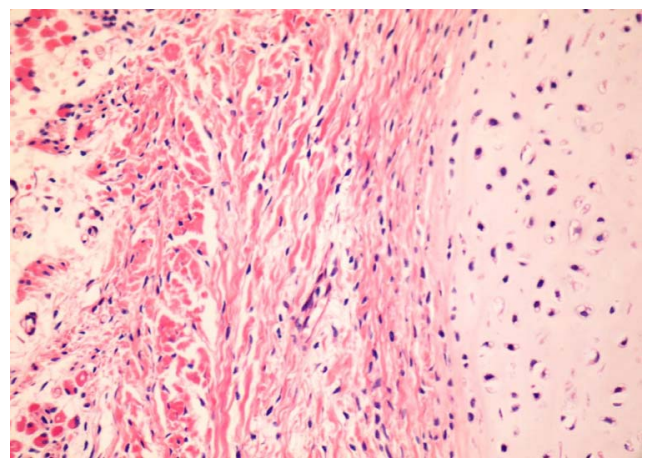

Figure 3. Disorganized cartilage (right side of the figure) and striated muscle fiber (left side of the figure) $(\mathrm{H} \& \mathrm{E} \times 200)$.

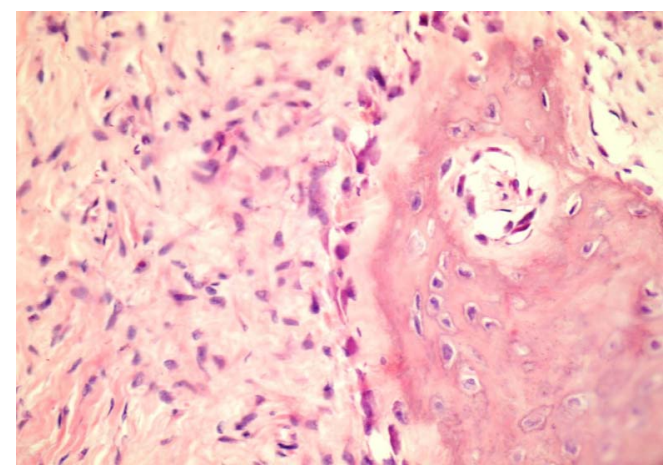

Figure 4. Fibrous tissue (left side of the figure) and bone (right side of the figure) $(\mathrm{H} \& \mathrm{E} \times 200)$. velopment may arise later in life. In the early phase of development, the primitive gut investigates into the umblical cord, and the well-formed intestinal mucosa can be seen in the cord up until the third month and occasionally even as late as the fourth month. It is possible to hypothesize that the abberrant germ cells can migrate through this evaginated hindgut and give rise to a teratoma of the umblical cord. If they progress into the loose connective tissue of the umblical cord and continue further migration, they may arrive at the fetal surface of the placenta between the amnion and chorion [2-6]. This theory is reported as the most probable one and almost all of the placental teratomas, as well as our case, are localized in this region.

\section{REFERENCES}

[1] N. Ahmed, V. Kale, H. Thakkar, et al., "Sonographic Diagnosis of Placental Teratoma," Journal of Clinical Ultrasound, Vol. 32, No. 3, 2004, pp. 98-101. doi:10.1002/jcu.10231

[2] K. Meinhard and S. Dimitrov, A. Nicolov, et al., "Placental teratoma," Pathology—Research and Practice, Vol. 195, No. 9, 1999, pp. 649-651. doi:10.1016/S0344-0338(99)80130-7

[3] R. Chandy, A. G. Korula and L. Seshadri, "Teratoma of the Placenta," Australian and New Zealand Journal of Obstetrics and Gynaecology, Vol. 42, No. 5, 2002, pp. 556-557. doi:10.1111/j.0004-8666.2002.548_6.x

[4] S. Elagöz, H. Aker and A. Çetin, "Placental Teratoma," The European Journal of Obstetrics \& Gynecology and Reproductive Biology, Vol. 80, No. 2, 1998, pp. 263-265. doi:10.1016/S0301-2115(98)00090-6

[5] H. Shimojo, N. Itoh, H. Shigematsu and T. Yamazaki, "Mature Teratoma of the Placenta," Pathology International, Vol. 46, No. 5, 1996, pp.372-375. doi:10.1111/j.1440-1827.1996.tb03623.x

[6] H. Fox and R. Butler-Manuel, "A Teratoma of the Placenta,” The Journal of Pathology and Bacteriology, Vol. 88, No. 1, 1964, pp. 137-140. doi:10.1002/path.1700880118 